Article

\title{
Open Reduction in Subtrochanteric Femur Fractures Is Not Accompanied by a Higher Rate of Complications
}

\author{
Tom Knauf ${ }^{1, * \mathbb{D}}$, Daphne Eschbach ${ }^{1}$, Benjamin Buecking ${ }^{2}$, Matthias Knobe ${ }^{3} \mathbb{D}$, Juliane Barthel ${ }^{1}$, \\ Katherine Rascher ${ }^{4}$, Steffen Ruchholtz ${ }^{1}$, Rene Aigner ${ }^{1}$, Carsten Schoeneberg ${ }^{5}$ (D) \\ and on behalf of the Registry for German Trauma DGU ${ }^{+}$
}

1 Center for Orthopaedics and Trauma Surgery, University Hospital Giessen and Marburg, 35039 Marburg, Germany; eschbach@med.uni-marburg.de (D.E.); barthelj@med.uni-marburg.de (J.B.); ruchholt@med.uni-marburg.de (S.R.); aignerr@med.uni-marburg.de (R.A.)

2 Center for Orthopaedics and Trauma Surgery, DRK-Kliniken Nordhessen, 34121 Kassel, Germany; buecking@drk-nh.de

3 Department of Orthopaedic and Trauma Surgery, Lucerne Cantonal Hospital, 6004 Lucerne, Switzerland; Matthias.knobe@luks.ch

4 AUC, Akademie der Unfallchirurgie GmbH, 80639 Munich, Germany; katherine.rascher@auc-online.de

5 Department of Orthopedic and Emergency Surgery, Alfried Krupp Hospital, 45131 Essen, Germany; carsten.schoeneberg@krupp-krankenhaus.de

* Correspondence: knauft@med.uni-marburg.de; Tel.: +49-6421-58-63174; Fax: +49-6421-58-66721

+ Working Committee on Geriatric Trauma Registry of the German Trauma Society (DGU).

\section{check for} updates

Citation: Knauf, T.; Eschbach, D.; Buecking, B.; Knobe, M.; Barthel, J.; Rascher, K.; Ruchholtz, S.; Aigner, R.; Schoeneberg, C.; on behalf of the Registry for German Trauma DGU. Open Reduction in Subtrochanteric Femur Fractures Is Not Accompanied by a Higher Rate of Complications. Medicina 2021, 57, 659. https:// doi.org/10.3390/medicina57070659

Academic Editor: Mikk Jürisson

Received: 19 May 2021

Accepted: 23 June 2021

Published: 27 June 2021

Publisher's Note: MDPI stays neutral with regard to jurisdictional claims in published maps and institutional affiliations.

Copyright: (c) 2021 by the authors Licensee MDPI, Basel, Switzerland. This article is an open access article distributed under the terms and conditions of the Creative Commons Attribution (CC BY) license (https:// creativecommons.org/licenses/by/ $4.0 /)$.

\begin{abstract}
Background and Objectives: Hip fractures are among the most typical geriatric fractures Subtrochanteric fractures are considered difficult to treat, and, to date, there is no consensus on the optimal surgical treatment. Materialis and Methods: We analyzed data from the Registry for Geriatric Trauma, which includes patients $\geq 70$ years old with hip fractures or periprosthetic fractures requiring surgery (21,734 patients in 2017-2019). For this study, we analyzed only the subgroup of patients with a subtrochanteric fracture. We analyzed the difference between closed and open surgical methods on a range of outcomes, including mortality, mobility, length of acute hospital stay, and the need for surgical revisions. Results: A total of 506 patients with subtrochanteric fractures were analyzed in this study. The median age was 85 years (interquartile range of $81-89)$. About $21.1 \%(n=107)$ were operated on with a closed technique, $73.3 \%(n=371)$ with open reduction without using a cerclage, and $5.53 \%(n=28)$ with open reduction with the additional use of one or more cerclage wires. A total of $3.56 \%(n=18)$ of the patients had complications requiring operative revision, most commonly soft tissue interventions (open vs. closed reduction-3.26\% vs. $4.67 \%)(p=0.687)$. Patients treated with open reduction were significantly more mobile 7 days after surgery $(p=0.008)$, while no significant effects on mortality $(p=0.312)$, length of hospital stay $(p=0.968)$, or surgical complications $(p=0.687)$ were found. Conclusion: Proper reduction is the gold standard practice for successful union in subtrochanteric fractures. This study shows that open reduction is not associated with a higher complication rate but does lead to increased mobility 7 days after operation. Therefore, in case of doubt, a good reduction should be aimed for, even using open techniques.
\end{abstract}

Keywords: subtrochanteric fracture; reduction; geriatric patient; hip fracture

\section{Introduction}

Due to demographic changes, the treatment of geriatric patients is gaining more attention nowadays. Hip fractures remain the most typical fragility fractures in geriatric patients. Despite great efforts in optimizing perioperative treatment and long-term rehabilitation programs, per- and subtrochanteric fractures are associated with high morbidity and mortality, reduced quality of life, and a loss of postoperative autonomy [1-4]. Of all proximal femur fracture types, subtrochanteric fractures account for $8-34 \%$ of the trochanteric fractures [3,5] and are associated with the worst outcomes $[3,6]$. 
Intramedullary stabilization is the favored surgical procedure for these fractures [3,7]. However, it is not clear which type of reduction (open vs. closed) is best [8-12]. Some studies have found that open reduction leads to a more anatomic reposition and lower malunion rates $[2,8,9,11]$. In contrast, other authors report higher non-union rates and complications regarding soft tissue healing with open reduction [13,14]. A retrospective analysis by Shukla et al. showed no increase of complications with regard to wound infections, recovery rates, and some other minor complications, independent of the greater intraoperative soft tissue trauma following open reduction [8]. Codesido et al. support these findings. Despite longer operation times for patients that were treated with open reduction, they found reduced lengths of hospital stay by 2 days and showed an improved health-related quality of life (EQ-5D) compared to closed reduction patients [15]. However, the results of the current literature are inconsistent $[13,16]$. Therefore, we analyzed the data of the Registry for Geriatric Trauma (ATR-DGU) to study the differences of closed vs. open reduction of subtrochanteric femoral fractures in an orthogeriatric treated collective. The primary outcome parameter was the occurrence of complications with a need for surgical revision. Secondary outcome parameters were mortality, mobility, and length of hospital stay. We hypothesized that the treatment of subtrochanteric fractures with open reduction does not lead to higher rates of surgical revisions.

\section{Materials and Methods}

\subsection{Data Source}

The ATR-DGU was founded by the German Trauma Society (DGU) in 2016. The ATR-DGU encompasses standardized, pseudonymized documentation of geriatric patients with a proximal femur fracture requiring surgery. The infrastructure for documentation, data management, and data analysis is provided by the Academy for Trauma Surgery (AUC-Akademie der Unfallchirurgie $\mathrm{GmbH}$ ). The scientific oversight is carried out by the Working Committee on Geriatric Trauma Registry (AK ATR) of the DGU. Participating centers transmit pseudonymized patient data via a web-based application into a central database. Approval for scientific data analysis from the ATR-DGU is granted via a peerreview process in accordance with the publication guidelines laid down by the AK ATR [17]. Currently, hospitals from Germany, Switzerland, and Austria contribute to the ATR-DGU, with a total of nearly 25,000 cases from about 100 hospitals. The present study is in accordance with the publication guidelines of the ATR-DGU and registered as ATR-DGU project ID 2020-007.

\subsection{Patient Inclusion}

The inclusion criteria of the ATR-DGU are hip fractures with a need for surgery and the age of 70 years or older. Patients who died before surgery were excluded. The data was collected during 5 relevant time periods: admission, preoperatively, during the first postoperative week, at discharge, and during an optional follow-up on the 120th postoperative day.

\subsection{Statistical Analyses}

Continuous variables were expressed as the median with an interquartile range (IQR), and categorical variables as counts and percentages. The variables were compared between the groups (open vs. closed reduction) using Wilcoxon-Mann-Whitney U-tests for continuous variables and chi-squared tests for categorical variables. A binary logistic regression was performed to further examine the influence of the open vs closed reduction on walking ability on the 7th post-operative day. As is common with registry data, not all information was available for each patient. All analyses were performed in $\mathrm{R}$ version 4.0.2.

\section{Results}

Between 2017 and 2019, 21,734 patients were entered into the ATR-DGU register. A total of 841 of those patients suffered from subtrochanteric fracture. Of these patients, 
786 were treated with an intramedullary nail. For 280 patients, there was no data on the operative treatment (open vs. closed reduction). After the exclusion of all incomplete datasets, it was possible to analyze the data from 506 patients from 75 hospitals. We further divided the patients into two groups: closed reduction $(n=107)$ and open reduction $(n=399)$.

The 120-day follow-up data was available for roughly one-third of these patients $(n=194)$.

\subsection{Baseline Characteristics}

The median age was 85 years (interquartile range (IQR) of $81-89)$ and $74.1 \%(n=375)$ of patients were female. About $76.4 \%(n=367$ patients) of the patients had an AmericanScoiety of Anaesthesiologists (ASA)-score $\geq 3$, indicating severe systemic disease, and almost half of the patients took anticoagulants prior to their fracture $(49.7 \% ; n=242)$. The median length of stay in the hospital was 17 days (IQR of 11-22). A total of $21.1 \%(n=107)$ of patients were treated with closed reduction, $73.3 \%(n=371)$ with open reduction without wire cerclage, and $5.53 \%(n=28)$ with open reduction and the use of a wire cerclage. The baseline characteristics and patient counts for each parameter can be found in Table 1.

Table 1. Baseline characteristics.

\begin{tabular}{|c|c|}
\hline Patient Characteristics & All $(n=506)$ \\
\hline \multicolumn{2}{|l|}{ Baseline Data-Initial Stay } \\
\hline Age (n) & $n=506$ \\
\hline Median (Interquartile Range) (IQR) & $85(81,89)$ \\
\hline Gender & $n=506$ \\
\hline Female & $74.1 \%(n=375)$ \\
\hline ASA Score & $n=480$ \\
\hline 1 & $0.417 \%(n=2)$ \\
\hline 2 & $23.1 \%(n=111)$ \\
\hline 3 & $67.9 \%(n=326)$ \\
\hline 4 & $8.12 \%(n=39)$ \\
\hline 5 & $0.417 \%(n=2)$ \\
\hline Type of Surgery (Subtrochanteric Fracture) & $n=506$ \\
\hline Intramedullary nail open reduction without wire cerclage & $73.3 \%(n=371)$ \\
\hline Intramedullary nail open reduction with wire cerclage & $5.5 \%(n=28)$ \\
\hline Intramedullary nail closed reduction & $21.1 \%(n=107)$ \\
\hline $\begin{array}{l}\text { Length of Stay (Median/IQR) }(n=463) \\
\text { (Survivors) }\end{array}$ & $17.04(11.06,22.08)$ \\
\hline \multicolumn{2}{|l|}{ Anticoagulation on Admission $(n=487)$} \\
\hline No anticoagulation & $50.3 \%(n=245)$ \\
\hline Vitamin $\mathrm{K}$ antagonist & $18.2 \%(n=44)$ \\
\hline Acetylsalicylic acid & $49.6 \%(n=120)$ \\
\hline Other thrombocyte aggregation inhibitors & $7.02 \%(n=17)$ \\
\hline Direct thrombin inhibitor (Dabigatran) & $3.72 \%(n=9)$ \\
\hline Direct factor Xa inhibitor (Rivaroxaban, Apixaban) & $22.3 \%(n=54)$ \\
\hline Heparin & $2.07 \%(n=5)$ \\
\hline Other & $2.07 \%(n=5)$ \\
\hline
\end{tabular}


Table 1. Cont.

\begin{tabular}{|c|c|}
\hline Patient Characteristics & All $(n=506)$ \\
\hline Surgical Complication (during initial stay) & $3.56 \%(n=18)$ \\
\hline Removal of implant or osteosynthesis & $11.1 \%(n=2)$ \\
\hline Revision of osteosynthesis & $22.2 \%(n=4)$ \\
\hline Soft tissue intervention & $66.7 \%(n=12)$ \\
\hline Others & $16.7 \%(n=3)$ \\
\hline Mortality & $(n=505)$ \\
\hline During initial stay & $7.52 \%(n=38)$ \\
\hline $\begin{array}{l}\text { Length of Stay (Median/IQR) ( } n=) \\
\text { (Survivors) }\end{array}$ & $\begin{array}{c}n=463 \\
17.04(11.06,22.08)\end{array}$ \\
\hline Discharge After Hospital (initial stay) & $n=461$ \\
\hline Home & $22.28 \%(n=105)$ \\
\hline Nursing home & $29.9 \%(n=138)$ \\
\hline Geriatric rehabilitation & $41.6 \%(n=192)$ \\
\hline Clinic for follow-up treatment & $3.90 \%(n=18)$ \\
\hline Other (different hospital, different department, other) & $1.74 \%(n=8)$ \\
\hline \multicolumn{2}{|l|}{ Baseline data-follow-up } \\
\hline \multicolumn{2}{|l|}{ Surgical Complication } \\
\hline Yes & $1.38 \%(n=7)$ \\
\hline Removal of implant or osteosynthesis & $42.9 \%(n=3)$ \\
\hline Revision of osteosynthesis & $14.3 \%(n=1)$ \\
\hline Conversion in total hip arthroplasty & $14.3 \%(n=1)$ \\
\hline Girdlestone & $14.3 \%(n=1)$ \\
\hline Soft tissue intervention & $14.3 \%(n=1)$ \\
\hline Others & $28.6 \%(n=2)$ \\
\hline \multicolumn{2}{|l|}{ Mortality } \\
\hline Yes & $2.57 \%(n=13)$ \\
\hline Current Location & $n=140$ \\
\hline Home & $72.9 \%(n=102)$ \\
\hline Nursing home & $25.7 \%(n=36)$ \\
\hline Hospital & $0.714 \%(n=1)$ \\
\hline Other & $0.714 \%(n=1)$ \\
\hline
\end{tabular}

ASA-Score:American-Society of Anaesthesiologists-Score.

\subsection{Primary Outcome Parameter}

"Complications requiring surgical revision" was defined as the primary outcome parameter. A total of $3.56 \%(n=18)$ of the patients suffered from such complications during the initial hospital stay. Soft tissue interventions were the most common surgical revisions performed (Table 1). Comparing open vs. closed reduction, $3.26 \%$ of the patients treated using open reduction required a revision surgery versus $4.67 \%$ of the patients treated with closed reduction, but this difference was not statistically significant $(p=0.687$ ) (Table 2; Figure 1). No significant difference regarding complications leading to revision surgery was seen in the follow-up data $(p=1)$ (Table 3$)$. 


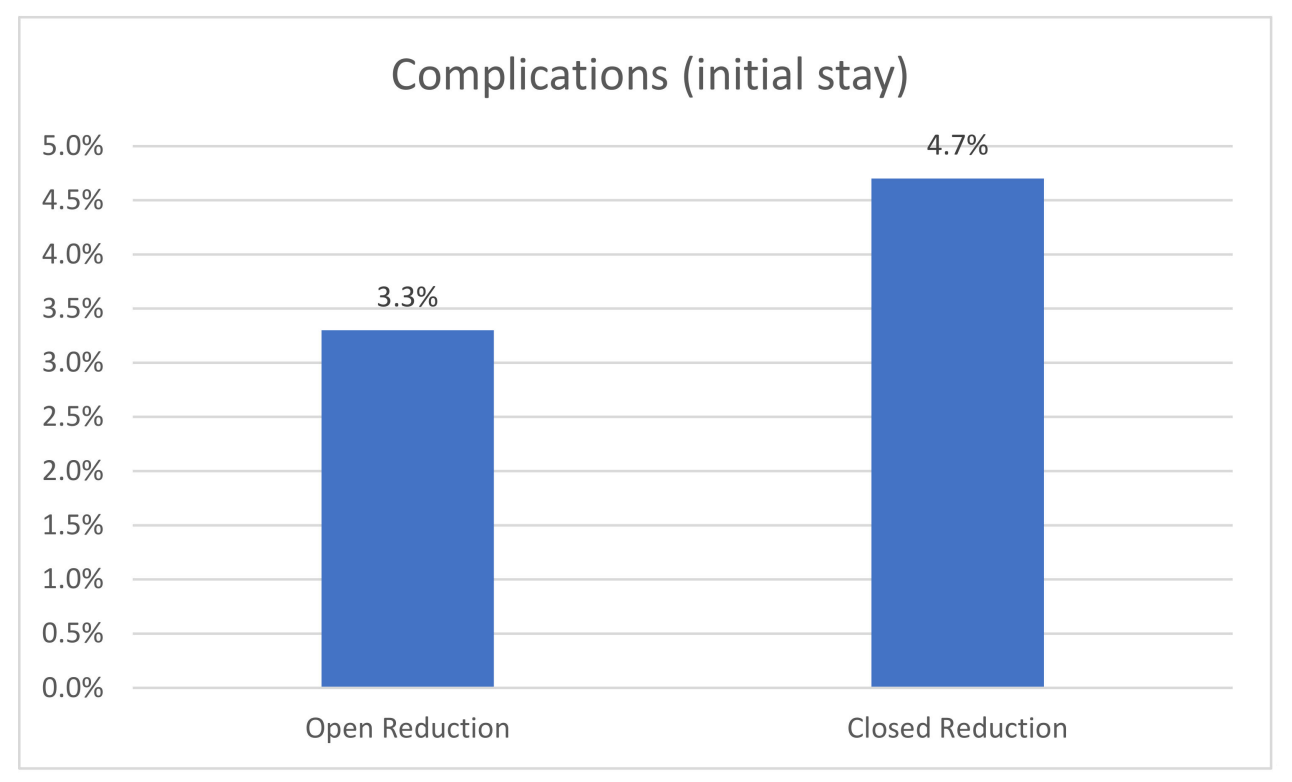

Figure 1. The rate of complications after open vs. closed reduction.

Table 2. Open vs. closed reduction (initial stay).

\begin{tabular}{|c|c|c|c|}
\hline & $\begin{array}{l}\text { Open Reduction } \\
\quad(n=399)\end{array}$ & $\begin{array}{c}\text { Closed Reduction } \\
(n=107)\end{array}$ & $p$ \\
\hline \multicolumn{4}{|l|}{ Baseline Data } \\
\hline Age $n$ & 399 & 107 & $0.327^{*}$ \\
\hline Median (Interquartile Range) (IQR) & $85(81 ; 89)$ & $84(80 ; 89)$ & \\
\hline Gender & & & $0.233^{+}$ \\
\hline Female & $301(75.4 \%)$ & $74(69.2 \%)$ & \\
\hline Male & $98(24.6 \%)$ & $33(30.8 \%)$ & \\
\hline ASA Score & & & $0.198^{+}$ \\
\hline 1 & $1(0.3 \%)$ & $1(1.0 \%)$ & \\
\hline 2 & $92(24.4 \%)$ & $19(18.4 \%)$ & \\
\hline 3 & $256(67.9 \%)$ & $70(68.0 \%)$ & \\
\hline 4 & $26(6.9 \%)$ & $13(12.6 \%)$ & \\
\hline 5 & $2(0.5 \%)$ & & \\
\hline Anticoagulation on Admission & & & $0.088^{+}$ \\
\hline No Anticoagulation & $48.2 \%(n=185)$ & $58.3((n=60)$ & \\
\hline \multicolumn{4}{|l|}{ Walking Ability Before Fracture } \\
\hline Without aids/forearm crutches & $168(46.2 \%)$ & $52(52 \%)$ & \\
\hline Walker & $128(35.2 \%)$ & $28(28 \%)$ & $0.538^{+}$ \\
\hline Only at home & $58(15.9 \%)$ & $16(16 \%)$ & \\
\hline No walking possible & $10(2.8 \%)$ & $4(4 \%)$ & \\
\hline Full Weight Bearing of the Fracture is Allowed & & & 0.073 \\
\hline Yes & $66.0 \%(n=262)$ & $75.7 \%(n=81)$ & \\
\hline \multicolumn{4}{|l|}{ Primary Outcome Parameter } \\
\hline Surgical Complication & & & 0.687 \\
\hline
\end{tabular}


Table 2. Cont.

\begin{tabular}{|c|c|c|c|}
\hline & $\begin{array}{c}\text { Open Reduction } \\
\quad(n=399)\end{array}$ & $\begin{array}{l}\text { Closed Reduction } \\
\quad(n=107)\end{array}$ & $p$ \\
\hline Yes & $3.26 \%(n=13)$ & $4.67 \%(n=5)$ & \\
\hline Soft tissue intervention & $2.5 \%(n=10)$ & $1.8 \%(n=2)$ & \\
\hline Removal of Implant or osteosynthesis & $0.3 \%(n=1)$ & $0.9 \%(n=1)$ & \\
\hline Revision of osteosynthesis & $0.5 \%(n=2)$ & $1.8 \%(n=2)$ & \\
\hline Periosteosynthetic fracture & $0 \%(n=0)$ & $0.9 \%(n=1)$ & \\
\hline Others & $0.8 \%(n=3)$ & $0 \%(n=0)$ & \\
\hline \multicolumn{4}{|l|}{ Secondary Outcome Parameter } \\
\hline Discharge After Hospital (initial stay) (Survivors) & $n=366$ & $n=95$ & $p=0.846$ \\
\hline Home & $23.5 \%(n=86)$ & $20 \%(n=19)$ & \\
\hline Nursing home & $30.3 \%(n=111)$ & $28.4 \%(n=27)$ & \\
\hline Geriatric rehabilitation & $40.4 \%(n=148)$ & $46.3 \%(n=44)$ & \\
\hline Clinic for follow-up treatment & $4.10 \%(n=15)$ & $3.16 \%(n=3)$ & \\
\hline Other & $1.64 \%(n=6)$ & $2.11 \%(n=2)$ & \\
\hline Mortality & $6.78 \%(n=27)$ & $10.3 \%(n=11)$ & 0.312 \\
\hline Change in Walking Ability (pre-fracture to 7 days post-op) & & & $0.008^{+}$ \\
\hline Worse & $61.8 \%(n=218)$ & $77.1 \%(n=74)$ & \\
\hline No change & $28.9 \%(n=102)$ & $20.8 \%(n=20)$ & \\
\hline Better & $9.4 \%(n=33)$ & $2.1 \%(n=2)$ & \\
\hline Lengths of stay (days) (Survivors) & $n=367$ & $n=96$ & 0.968 \\
\hline Median (IQR) & $17(11,22.1)$ & $16.6(12,21.6)$ & \\
\hline
\end{tabular}

${ }^{*}$ Mann-Whitney U test; ${ }^{+}$Chi-square test; ${ }^{\prime}$ Wilcox test.

Table 3. Open reduction vs. closed reduction (follow-up).

\begin{tabular}{|c|c|c|c|}
\hline & Open Reduction & Closed Reduction & \\
\hline Follow-Up Conducted & $38.8 \%(n=155)$ & $36.4 \%(n=39)$ & \\
\hline \multicolumn{4}{|l|}{ Primary Outcome Parameter } \\
\hline Surgical Complication & $n=130$ & $n=36$ & $p=1$ \\
\hline Yes & $3.9 \%(n=5)$ & $5.6 \%(n=2)$ & \\
\hline Soft tissue intervention & $n=0$ & $n=1$ & \\
\hline Removal of implant or osteosynthesis & $n=2$ & $n=1$ & \\
\hline Revision of osteosynthesis & $n=1$ & $n=0$ & \\
\hline Conversion in HTEP & $n=1$ & $n=0$ & \\
\hline Girdlestone & $n=1$ & $n=0$ & \\
\hline Others & $n=1$ & $n=1$ & \\
\hline \multicolumn{4}{|l|}{ Secondary Outcome Parameter } \\
\hline Mortality & $\begin{array}{c}8.39 \%(n=13 \\
\text { additional deaths in } \\
\text { FU Period })\end{array}$ & $0 \%(n=0)$ & 0.075 \\
\hline $\begin{array}{l}\text { Change in Walking Ability (pre-fracture to 120-day } \\
\text { follow-up) }\end{array}$ & & & $0.82^{+}$ \\
\hline
\end{tabular}


Table 3. Cont.

\begin{tabular}{ccc}
\hline & Open Reduction & Closed Reduction \\
\hline Worse & $65(60.2 \%)$ & $19(59.4 \%)$ \\
\hline No change & $39(36.1 \%)$ & $11(34.4 \%)$ \\
\hline Better & $4(3.7 \%)$ & $2(6.3 \%)$ \\
\hline
\end{tabular}

\subsection{Secondary Outcome Parameters}

Whether a fracture was treated with open or closed reduction had a significant influence on the change in walking ability (pre-fracture to seven days post-surgery) ( $p=0.008$; Table 2). A total of $38.3 \%$ of the patients treated with open reduction had at least the same level of mobility compared to the pre-fracture level, while only $22.9 \%$ of the patients treated with closed reduction had that level of mobility. Patients treated with open reduction had a mortality rate at the 120 -day follow-up of $8.4 \%$. vs. $0 \%$ in the closed reduction group; however, due to the small sample size, this difference was not statistically significant $(p=0.075)$.

The positive influence of open reduction on walking ability on the seventh day after surgery was confirmed in a multivariate logistic regression adjusted for age, gender, ASA score, and mobility before the fracture (odds ratio- $2.07 ; 95 \%$ confidence interval $(1.25$; 3.42); $p=0.004)$.

\section{Discussion}

In order to ensure optimal fracture care, visualization of the fracture is important. While often a 2-plane x-ray is sufficient, there are cases where computer tomography (CT) with 3D reconstruction may be used for better visualization of the fracture $[18,19]$. It is broadly recognized that proper reduction is necessary for the successful union in subtrochanteric fractures $[2,9,11]$. Higher non-union rates and complications regarding soft tissue healing are feared complications of open reductions $[13,14]$. The aim of this study was to evaluate whether the reduction type (open vs. closed) of subtrochanteric femoral fractures influenced surgical revision rates, mortality, mobility, or length of hospital stay for geriatric hip fracture patients.

\subsection{Primary Outcome Parameter}

In order to provide a suitable reduction of subtrochanteric fractures, different techniques have been described, from closed reduction to mini-open procedures and open reduction using cerclage wires and cables. Some authors hesitate to perform open reduction because of prolonged wound healing, soft tissue complications, and the risk of nonunion $[13,14]$. They recommend open reduction only after all other closed reduction options have been exhausted [11]. In our study, the type of reduction (open vs. closed) showed no significant difference with regard to complications (open reduction: $3.3 \%$ vs. closed reduction: $4.7 \%$ ). When performed properly, open reduction might be one key point to avoid malalignment without the risk of further soft tissue complications. Krappinger et al. studied risk factors for nonunion after intramedullary nailing of subtrochanteric fractures. In their study, neither open reduction nor the use of wire cerclage were significant risk factors for nonunion [10]. This is in contrast to malalignment, which has been shown to be a risk factor for nonunion [8-10]. Kasha et al. concluded that regardless of the method chosen, the key point to reduce the risk of complications is adequate reduction [11]. Trikha et al. concluded, in their retrospective analysis, minimally invasive cerclage wire application to be beneficial for anatomical reconstruction in difficult subtrochanteric fractures [12]. Therefore, the high rate of open reduction is not surprising. A total of $78.9 \%$ of the fractures of patients included in the ATR-DGU were treated with open reduction. This rate is quite high compared with rates described by other authors (48.1\%) [20]. Contrary to this, only $5.5 \%$ of the fractures were treated with an additional wire cerclage. This rate is lower 
compared to the earlier literature (14.8\%) [20]. Differences may be due to the different study collectives that were described. Our study only focused on geriatric trauma patients, whereas age was not an exclusion criterion in the other studies [20]. Additionally, all of our patients were treated in an orthogeriatric setting [21].

\subsection{Secondary Outcome Parameters}

According to Dubljanin et al., the functional level at discharge is the main determinant of 1-year mortality for hip fracture patients [22]. Therefore, this may serve as a screening tool to predict the further outcome for these patients. Looking at the mobility of hip fracture patients in our study, on the seventh day after surgery, $69.2 \%$ of the patients had some walking ability. A closer look at the change in mobility of these patients on the seventh day after surgery showed that $38.3 \%$ of the patients treated with open reduction had at least the same level of mobility compared to the pre-fracture level, while only $22.9 \%$ of the patients treated with closed reduction had that level of mobility. This increased mobility of patients treated using open reduction is quite remarkable when taking into account that only in $66 \%$ of the patients was full weight-bearing allowed $(75.7 \%$ of the patients with closed reduction). None of the other parameters analyzed (mortality, length of hospital stay, surgical complication, and discharge location) showed a significant difference between the open and closed reduction groups during the initial stay or the follow-up. The results of the follow-ups must be viewed with caution, as they were evaluated in only one-third of the patients. Additionally, it must also be critically mentioned here that the follow-up was relatively short at 120 days. It is possible that an association between improved mobility and decreased mortality would be seen if the follow-up was conducted later. In contrast, we found a tendency for higher mortality in the open reduction group $(8.4 \%$. vs. $0 \%$ in the closed reduction group). Therefore, we can draw no conclusions about the influence of reduction type on mortality.

\subsection{Strengths and Limitations of the Study}

As a limitation of this study, it has to be mentioned that not all items were collected from all patients, which is unfortunately common in registry studies. Additionally, the register lacks information regarding the quality of reduction and the quality of the union after 120 days, which would have been interesting in evaluating the postoperative result. As already mentioned above, the low follow-up rate is a further limiting factor.

Whether or not an additional cerclage had an impact on the outcome parameters would also be interesting to evaluate. Unfortunately, only 5.5\% of the patients were treated with an additional cerclage, making this analysis not possible. Therefore, patients treated with an additional cerclage were included in the "open-reduction" group.

Unfortunately, we were not able to reproduce which criteria led the surgeons to perform an open reduction, since this parameter was not collected in the registry study.

Nevertheless, the strength of this study is the large number of patients suffering from this special type of fracture. Patients from multiple centers all over Germany, Austria, and Switzerland were included in this study, which has to be mentioned as an additional strength of this study. Furthermore, the requirement that data was only obtained from orthogeriatric centers makes this collection a very uniform one and reduces the multiple confounding factors that may make the evaluation of such treatment data difficult.

\section{Conclusions}

Subtrochanteric fractures remain a rare subtype of proximal femoral fractures in the geriatric trauma population. Proper reduction is necessary for the successful healing of subtrochanteric fractures. Some surgeons are hesitant to perform open reduction due to concerns about soft tissue healing and other complications. Our study showed that open reduction was not accompanied by a higher complication rate, mortality rate, nor an increased length of hospital stay. Seven days after surgery, patients treated with open reduction had better mobility, which is an important step in the recovery of geriatric 
patients. There might be situations in which a less than optimal reduction can be accepted in favor of a more minimally invasive operation. However, in the case of a subtrochanteric fracture, a critical evaluation should be made. In case of doubt, a good reduction should be aimed for, even if that means performing an open reduction.

Author Contributions: T.K.: conceptualization, data curation, writing-original draft; B.B.: conceptualization, writing-review and editing; J.B.: data curation, writing-review and editing; K.R.: methodology, formal analysis, writing - review and editing; M.K.: conceptualization, writingreview and editing; D.E.: data curation, writing-review and editing; S.R.: conceptualization, writing-review and editing, supervision; R.A.: conceptualization, data curation, writing-review and editing: C.S.: conceptualization, data curation, writing-review and editing; on behalf of the Registry for Geriatric Trauma (ATR-DGU). All authors have read and agreed to the published version of the manuscript.

Funding: This research received no external funding. No additional financial support for the execution of the study was received.

Institutional Review Board Statement: The study was conducted according to the guidelines of the Declaration of Helsinki, and approved by the Ethics Committee of Philipps University Marburg (Ethical Approval Code: AZ 46/16; date: 5 April 2018).

Informed Consent Statement: Informed consent was obtained from all subjects involved in the study.

Data Availability Statement: The analyzed datasets of this study are available from the corresponding author on reasonable request.

Conflicts of Interest: The corresponding author declares, on behalf of all the authors, that there are no conflicts of interest.

\section{References}

1. Marks, R. Hip fracture epidemiological trends, outcomes, and risk factors, 1970-2009. Int. J. Gen. Med. 2009, 3, 1-17. [CrossRef]

2. Miedel, R.; Törnkvist, H.; Ponzer, S.; Söderqvist, A.; Tidermark, J. Musculoskeletal function and quality of life in elderly patients after a subtrochanteric femoral fracture treated with a cephalomedullary nail. J. Orthop. Trauma 2011, 25, 208-213. [CrossRef] [PubMed]

3. Buecking, B.; Ruchholtz, S. Trochanteric Fractures-Surgical Treatment and Short Term Outcome. OUP Orthopädische Unf. Prax. 2012, 1, 153-159.

4. Carow, J.; Carow, J.B.; Coburn, M.; Kim, B.-S.; Bücking, B.; Bliemel, C.; Bollheimer, L.C.; Werner, C.J.; Bach, J.P.; Knobe, M. Mortality and cardiorespiratory complications in trochanteric femoral fractures: a ten year retrospective analysis. Int. Orthop. 2017, 41, 2371-2380. [CrossRef] [PubMed]

5. Boyd, H.B.; Griffin, L.L. Classification and treatment of trochanteric fractures. Arch. Surg. 1949, 58, 853-866. [CrossRef] [PubMed]

6. Parker, M.; Dutta, B.; Sivaji, C.; Pryor, G. Subtrochanteric fractures of the femur. Injury 1997, 28, 91-95. [CrossRef]

7. AWMF. Leitlinie Pertrochantäre Oberschenkelfraktur. 2015. Accessed on: 7 July 2020.

8. Shukla, S.; Johnston, P.; Ahmad, M.; Wynn-Jones, H.; Patel, A.; Walton, N. Outcome of traumatic subtrochanteric femoral fractures fixed using cephalo-medullary nails. Injury 2007, 38, 1286-1293. [CrossRef] [PubMed]

9. Codesido-Vilar, P.; Mejía-Casado, A.; Riego-Fernández, J.; Rodriguez-Casas, N.; García-Cabanas, S.; Rivas-Felice, J.; GarcíaQuevedo, L. Consequences of quality of reduction on osteosynthesis complications and quality of life in elderly patients with subtrochanteric fracture. Rev. Española Cirugía Ortopédica Traumatol. 2018, 62, 240-247. [CrossRef]

10. Krappinger, D.; Wolf, B.; Dammerer, D.; Thaler, M.; Schwendinger, P.; Lindtner, R.A. Risk factors for nonunion after intramedullary nailing of subtrochanteric femoral fractures. Arch. Orthop. Trauma Surg. 2019, 139, 769-777. [CrossRef] [PubMed]

11. Kasha, S.; Yalamanchili, R.K. Management of subtrochanteric fractures by nail osteosynthesis: A review of tips and tricks. Int. Orthop. 2019, 44, 645-653. [CrossRef] [PubMed]

12. Trikha, V.; Das, S.; Agrawal, P.; Arkesh, M.; Dhaka, S.K. Role of percutaneous cerclage wire in the management of subtrochanteric fractures treated with intramedullary nails. Chin. J. Traumatol. 2018, 21, 42-49. [CrossRef] [PubMed]

13. Yoon, Y.-C.; Jha, A.; Oh, C.-W.; Durai, S.K.; Kim, Y.-W.; Kim, J.-H.; Oh, J.-K. The pointed clamp reduction technique for spiral subtrochanteric fractures: A technical note. Injury 2014, 45, 1000-1005. [CrossRef] [PubMed]

14. Malik, M.H.A.; Harwood, P.; Diggle, P.; Khan, S.A. Factors affecting rates of infection and nonunion in intramedullary nailing. J. Bone Jt. Surgery Br. Vol. 2004, 86, 556-560. [CrossRef]

15. Codesido, P.; Mejía, A.; Riego, J.; Ojeda-Thies, C. Subtrochanteric fractures in elderly people treated with intramedullary fixation: quality of life and complications following open reduction and cerclage wiring versus closed reduction. Arch. Orthop. Trauma Surg. 2017, 137, 1077-1085. [CrossRef] [PubMed] 
16. Boldin, C.; Seibert, F.J.; Fankhauser, F.; Peicha, G.; Grechenig, W.; Szyszkowitz, R. The proximal femoral nail (PFN)-A minimal invasive treatment of unstable proximal femoral fractures: A prospective study of 55 patients with a follow-up of 15 months. Acta Orthop. Scand. 2003, 74, 53-58. [CrossRef] [PubMed]

17. AUC-Akademie der Unfallchirurgie; Arbeitskreis AltersTraumaRegister DGU. The geriatric trauma register of the DGU—current status, methods and publication guidelines. Unfallchirurg 2019, 122, 820-822. [CrossRef]

18. Kani, K.K.; Porrino, J.A.; Mulcahy, H.; Chew, F.S. Fragility fractures of the proximal femur: review and update for radiologists. Skelet. Radiol. 2019, 48, 29-45. [CrossRef] [PubMed]

19. Tevanov, I.; Liciu, E.; Chirila, M.O.; Dusca, A.; Ulici, A. The use of 3D printing in improving patient-doctor relationship and malpractice prevention. Rom. J. Leg. Med. 2017, 25, 279-282. [CrossRef]

20. Hoskins, W.; Bingham, R.; Joseph, S.; Liew, D.; Love, D.; Bucknill, A.; Oppy, A.; Griffin, X. Griffin, Subtrochanteric fracture: The effect of cerclage wire on fracture reduction and outcome. Injury 2015, 46, 1992-1995. [CrossRef] [PubMed]

21. Knobe, M.; Böttcher, B.; Coburn, M.; Friess, T.; Bollheimer, L.C.; Heppner, H.J.; Werner, C.J.; Bach, J.-P.; Wollgarten, M.; Poßelt, S.; et al. Geriatric Trauma Center DGU®: Evaluation of clinical and economic parameters: A pilot study in a german university hospital. Unfallchirurg 2019, 122, 134-146. [CrossRef] [PubMed]

22. Dubljanin-Raspopović, E.; Marković-Denić, L.; Marinković, J.; Nedeljković, U.; Bumbaširević, M. Does early functional outcome predict 1-year mortality in elderly patients with hip fracture? Clin. Orthop. Relat. Res. 2013, 471, 2703-2710. [CrossRef] 